\title{
Prevalence of gastrointestinal stromal tumour (GIST) in the United Kingdom at different therapeutic lines: an epidemiologic model
}

\author{
Justyna M Starczewska Amelio ${ }^{1}$, Javier Cid Ruzafa ${ }^{1 *}$, Kamal Desai $^{1}$, Spiros Tzivelekis$^{2}$, Dominic Muston $^{3}$, \\ Javaria Mona Khalid', Philip Ashman ${ }^{3}$ and Andrew Maguire ${ }^{1}$
}

\begin{abstract}
Background: The prevalence of patients with gastrointestinal stromal tumourgst (GIST) who fail currently available treatments imatinib and sunitinib (third-line treatment-eligible GIST) is unknown, but is expected to be below an ultra-orphan disease threshold of 2/100,000 population used in England and Wales. Our study was designed to estimate the prevalence and absolute number of UK patients with unresectable/metastatic GIST at first-, second- and eventually third-line treatment.

Methods: Our open population model estimates the probability that the prevalence of UK third-line treatment-eligible GIST patients will remain under the ultra-orphan disease threshold. Model parameters for incidence, proportion of unresectable/metastatic disease and survival estimates for GIST patients were obtained from a targeted literature review and a UK cancer register. The robustness of the results was checked through differing scenarios taking extreme values of the input parameters.

Results: The base-case scenario estimated a prevalence of third-line treatment-eligible GIST of 1/100,000 and a prevalence count of 598 with a $99.9 \%$ likelihood of being below the ultra-orphan disease threshold. The extreme scenarios, one-way and probabilistic sensitivity analyses and threshold analysis confirmed the robustness of these results.

Conclusions: The prevalence of third-line treatment-eligible GIST is very low and highly likely below the ultra-orphan disease threshold.
\end{abstract}

Keywords: Epidemiology, Prevalence, Gastrointestinal stromal tumour, GIST, Model, Ultra-orphan disease

\section{Background}

Gastrointestinal stromal tumours (GIST) are relatively rare soft tissue mesenchymal tumours occurring in the gastrointestinal tract, originating in the interstitial cells of Cajal involved in the regulation of the digestive system [1,2]. Recent estimates of GIST annual incidence quoted in the United Kingdom (UK) range from 1.321.50 per 100,000 population, although none appear population-based [3,4], equivalent to approximately 800-900 new cases each year [4]. There have been no UK prevalence studies of GIST published to date, although reports from western Sweden and Hong Kong

\footnotetext{
*Correspondence: javier.cid@evidera.com

'Health Economics and Epidemiology, Evidera, Metro Building, 6th floor, No.1 Butterwick, London W6 8DL, UK

Full list of author information is available at the end of the article
}

have estimated prevalence at 12.9 per 100,000 [5] and 13.4-15.6 per 100,000 [6], respectively. Epidemiologic estimates of GIST in the UK have improved since the diagnostic coding of GIST was introduced in the third edition of the International Classification of Disease for Oncology (ICD-O), in 2000. Studies conducted before this period used the terms leiomyoma, leiomyosarcoma or leiomyoblastoma to identify GIST [2], likely resulting in overestimates. Some GIST have been diagnosed as benign and malignant mesenchymal lesions, tumours of the autonomic and peripheral nervous systems, or benign and malignant tumours not further classified; hence, these terms have been used sometimes to identify patients with a potential GIST diagnosis [5].

Currently only resection, dependent on early stage diagnosis, offers a potential cure. The proportion of patients

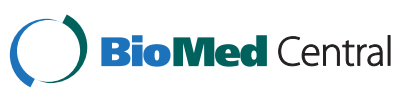


who are not eligible for resection and have metastatic/ unresectable disease at diagnosis has been reported in the United States (US), Canada and other European populations as varying between $13 \%$ and $50 \%$ [4,7-15]. The National Institute for Health and Care Excellence (NICE) imatinib appraisal has described the proportion of patients with metastatic/unresectable GIST as between 10\% and $30 \%$ [4]. For these patients, two lines of systemic therapy were introduced: first-line imatinib and second-line sunitinib in 2001 and 2006, respectively. Among patients who experience both imatinib and sunitinib treatment failure (referred to here as 'third-line treatment-eligible GIST'), current treatment options are limited to further imatinib rechallenge at increased dose, participation in clinical trials or best supportive care [16].

The prevalence of GIST patients eligible for third-line treatment in the UK is not known, but is expected to be low and potentially below orphan and ultra-orphan disease thresholds. In the European Union (EU), an orphan disease is defined as having a prevalence of less than 50 per 100,000 [17]; in England and Wales, NICE has suggested that conditions with a prevalence of less than 2 per 100,000 population may be considered ultra-orphan [18]. Given the importance of GIST prevalence on orphan or ultra-orphan disease status, our study was designed to estimate the prevalence and absolute number (i.e., prevalence count) of UK patients with unresectable/ metastatic GIST at first-, second- and eventually thirdline treatment. We developed an open-population model that estimated the number of subjects at each stage of treatment based on model parameters for GIST incidence, proportion of unresectable/metastatic GIST and survival estimates for GIST patients. Data to inform the model parameters were based on targeted literature review and data from a UK cancer register.

\section{Methods \\ Data sources}

To calculate the incidence of GIST, data were requested from all 11 cancer registers in the UK. Cancer registers responded to our query but only one register made data available: the West Midlands Cancer Intelligence Unit (WMCIU) from 2007 to 2010, owing to the recent introduction and variability in uptake of the specific ICD-O diagnostic code for GIST across UK cancer registers [19]. The WMCIU makes anonymized and aggregated data publically accessible to researchers for a fee to cover the expenses associated to data extraction, and acknowledgement of its contribution. The WMCIU age and gender strata incidence rates were applied to the UK population age and gender distribution to obtain a 2010 UK standardised incidence rate. The total estimated UK population in 2010 is $62,262,100$ [20]. WMCIU GIST incidence estimates were consistent with available published literature, therefore supporting the quality of the data obtained from the registry $[3-5,8,11,19,21]$.

Other model parameters were obtained from a targeted literature review. These included: the proportion of metastatic or unresectable GIST; post-resection GIST relapse rates; progression-free survival (PFS) or time to tumour progression (TTP) on first-line treatment (imatinib); PFS or TTP on second-line treatment (sunitinib) and overall survival (OS) post-imatinib and -sunitinib treatment failures. For each of these parameters several references were screened from the literature. Internal validity of the specific parameter estimates obtained from the literature, or the degree to which the cited studies are free from systematic error, is supported by the peer review process of such studies and the consistency of their results, that also supports external validity or generalizability to the UK. External validity is also expected since the documented parameter value ranges were narrow and the parameters' base-case were chosen around mid-range values.

Sources of published data used to inform the model parameters are given in Table 1. While some data sources provided values in the units required by the model, others needed transformation. For example, survival figures in a given treatment state expressed as percent of surviving patients at a specific time (month or year) after treatment initiation required transformation into yearly rates before they could be used in the model. While we focused our literature searches on publications reporting results among UK patients, we considered it adequate to include publications from studies in the US, Canada and other European populations to increase the robustness of our model. To account for background mortality we used data from the 2010 UK Life Tables available through the UK Office for National Statistics [20] weighted by the West Midlands register GIST patient's age distribution (2007-2010) [19] and assumed that within 10-year age bands of patients, the incidence of GIST did not vary. WMCIU data and literature search strategy are described in the Additional file 1: Appendices.

\section{Model overview}

We constructed a model for calculating the prevalence of GIST in the UK population (Figure 1) that represents the flow of patients with GIST from first diagnosis to death via two possible treatment pathways and four treatment states.

In the first pathway, the newly diagnosed patients with resectable GIST have their stromal tumour removed surgically and remain in a recurrence-free state for several years before some of them relapse. At this point those who relapse enter a state of non-resectable metastatic GIST and are assumed to receive successful treatment with imatinib for approximately two years and, during 
Table 1 Model parameters

\begin{tabular}{|c|c|c|c|c|}
\hline Parameter & Base-case Value (SE) ${ }^{5}$ & $\begin{array}{l}\text { Min-max range for } \\
\text { one-way } \mathrm{SA}^{\$}\end{array}$ & $\begin{array}{l}\text { Distribution } \\
\text { for } \text { PSA }^{\$}\end{array}$ & References \\
\hline GIST $^{\$}$ incidence $(\Gamma)$ in person-years & $1.053 / 100000(S E=0.139 / 100000)$ & $0.52 / 100000$ to $1.50 / 100000$ & Gamma & {$[3-5,8,11,19,21,31,32]$} \\
\hline Proportion of resectable GIST (p) & $0.8(S E=0.05)$ & $0.50-0.90$ & Beta & {$[4,9,11-13,15,33]$} \\
\hline Post-resection GIST $\operatorname{TTT}^{\$}\left(\gamma_{2}\right)^{*}$ & $0.0464(\mathrm{SE}=0.0025)$ & $0.029-0.186$ & Gamma & [34-38] \\
\hline Imatinib-treated GIST TTT $\left(\gamma_{3}\right)^{*}$ & $0.351(S E=0.103)$ & $0.205-0.645$ & Gamma & {$[14,39-44]$} \\
\hline Sunitinib-treated GIST TTT $\left(\gamma_{4}\right)^{*}$ & $0.974(\mathrm{SE}=0.085)$ & $0.533-1.435$ & Gamma & {$[45-48]$} \\
\hline Third-line treatment-eligible GIST survival $\left(\gamma_{5}\right)^{*}$ & $0.904(\mathrm{SE}=0.10)$ & $0.439-1.066$ & Gamma & {$[24,25,49-53]$} \\
\hline Yearly background mortality & $0.0314(\mathrm{SE}=0.0023)$ & $0.0269-0.0359$ & Gamma & [20] \\
\hline
\end{tabular}

${ }^{\$} G I S T=$ gastrointestinal stromal tumour; $S E=$ standard error; $S A=$ sensitivity analysis; $P S A$ = probabilistic sensitivity analysis; $\pi T=$ time to transition; *Yearly rate assuming patients' survival followed an exponential distribution.

this time, they are assumed to be progression-free. Following the failure of imatinib treatment, patients receive sunitinib in a second progression-free state with duration of approximately nine months. Finally, patients enter a third state during which they receive a presumed third line of treatment. They will eventually exit this final state as they will die. The model also allows patient exit through the background mortality in each of the states.

In the second pathway, patients who are metastatic or unresectable at diagnosis move directly into the imatinib treatment state joining other patients from the first treatment pathway. From this point, all patients follow the same treatment pathway until death. The flow through the model is governed by difference equations which calculate the annual number of patients presenting with GIST and numbers on each treatment type (see Additional file 1: Appendices). The model parameters correspond to rates of progression of patients through the different treatment states. Rates of progression are derived from what we called 'time to transition' (TTT) from one state to the next. TTT corresponds to the total

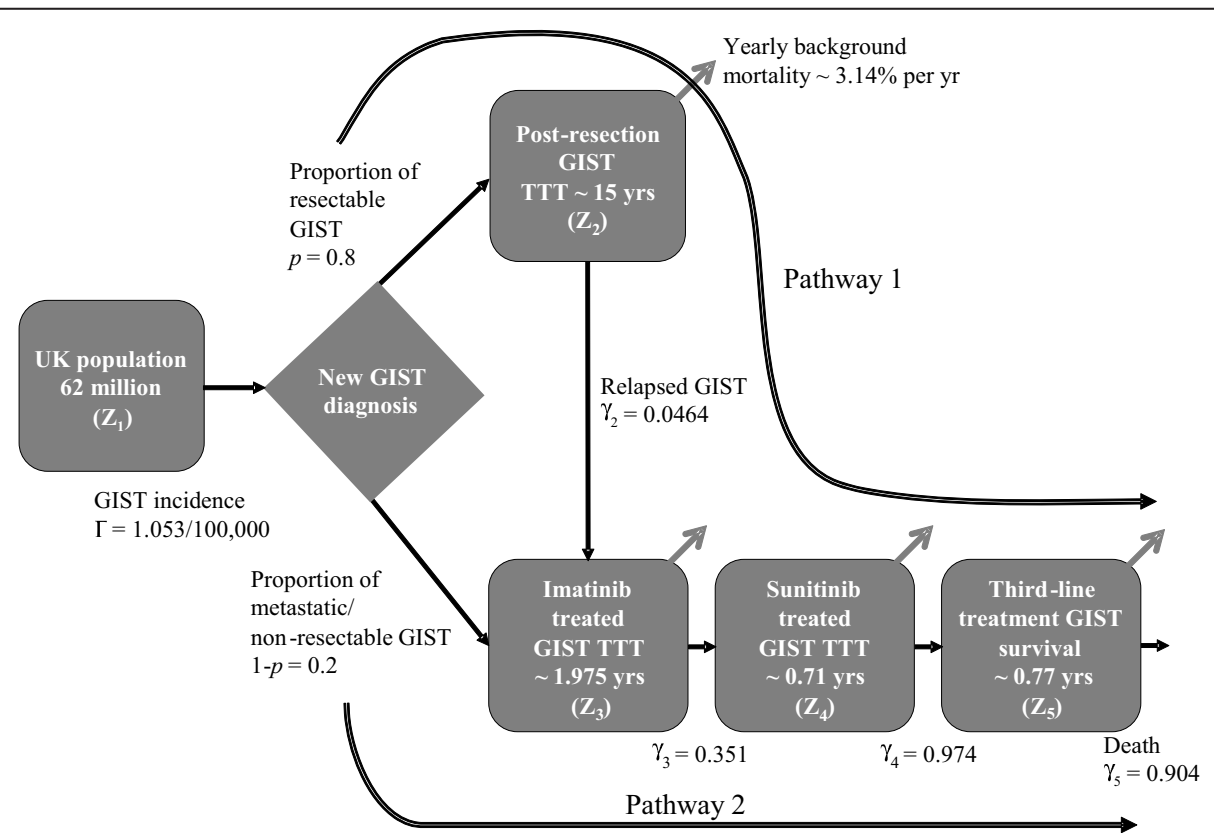

Figure 1 Model to assess GIST patient prevalence in the UK at different treatment stages. GIST = gastrointestinal stromal tumour; TTT = time to transition; UK = United Kingdom. The model parameters are given in Table $1 . Z_{1}$ refers to the total UK population and is fixed in all calculations at $62,262,000 . Z_{2}$ is the number of patients with non-metastatic GIST who have been resected and are currently recurrence free. $Z_{3}$ is the number of patients with non-resectable metastatic GIST and who are currently progression free while receiving treatment with imatinib. Similarly, $Z_{4}$ and $Z_{5}$ are the numbers of patients who are progression-free while receiving sunitinib and a third-line treatment, respectively. $\gamma_{2}$ is the annual rate of relapse which is estimated from the duration of relapse-free survival in this state. $\gamma_{3}$ is the annual rate of failure calculated from the duration of PFS and TTP on imatinib. $\gamma_{4}$ is the annual rate of failure calculated from the duration of PFS and TTP on sunitinib. $\gamma_{5}$ is the annual probability of failure calculated from the duration of OS on a range of investigational third-line treatments or best supportive care. $\Gamma=$ incidence of newly diagnosed GIST. $p=$ proportion. 
period of time on the current treatment as well as any period of discontinuation upon treatment failure until the next treatment line is initiated. TTT was therefore inferred from studies reporting PFS or time to tumour progression for all states, except for third-line treatmenteligible GIST for which we used OS.

\section{Model parameters, analysis and sensitivity analysis}

The model base-case scenario was defined by base-case values for each model parameter. All seven parameters in the model require four values to be specified (Table 1). The first is a base-case parameter estimate, while the remaining three (minimum value, maximum value, standard error) are necessary to express the uncertainty around the base-case value. Parametric uncertainty analyses were conducted through one-way and probabilistic sensitivity analysis (PSA) for the base-case and alternative scenarios. Univariate or one-way sensitivity analysis consisted of varying each parameter individually between its assumed minimum and maximum values, which were informed by the literature review, while fixing all other parameters at their base-case estimate. Thus, parameters which are most influential on model results can be identified.

The PSA consisted of varying all parameter values simultaneously by sampling each parameter 5,000 times from statistical distributions, which are specified by the mean (base-case parameter estimate) and standard error of each parameter. The beta distribution is valued between 0 and 1 and is employed in the model to represent the proportion of subjects at diagnosis with resectable GIST. The gamma distribution is strictly positively valued and is suited to model event rates, representing the rates of transition between each of the treatment states. In Table 1 we specified the preferred source for the base-case value and its standard error for each model parameter to obtain base-case estimates and to perform PSA, which provided credibility intervals for each model outcome.

Given the importance of the choice of two of the basecase values on model results, three alternative scenarios were defined based on higher GIST incidence, higher survival assumptions for third-line treatment-eligible GIST and higher for both incidence and third-line treatment-eligible GIST survival. The three aforementioned alternative scenarios were chosen by combining extreme values of the two most influential parameters from the results of the univariate sensitivity analyses.

We also performed threshold analysis. We explored what the incidence of GIST and the survival of third-line treatment-eligible GIST patients (two most influential parameters) would need to be to reach the 2 per 100,000 population prevalence figure corresponding with NICE ultra-orphan disease threshold. Threshold analysis was performed to address this question for each of the two parameters, while fixing all other parameter values.

\section{Model outcomes}

Model outcomes for each scenario included absolute number and prevalence per 100,000 population of all patients with GIST, patients in first-line (receiving imatinib) and second-line (receiving sunitinib) treatment and third-line treatment-eligible GIST patients who experienced imatinib and sunitinib treatment failures. Each outcome was expressed with $95 \%$ credibility intervals whose upper and lower limits were determined by the $2.5 \%$ and $97.5 \%$ percentiles of the outcomes obtained from the PSA. The PSA also permitted estimation of the probability that overall and third-line treatment-eligible GIST populations met orphan or ultra-orphan disease thresholds used in the UK.

\section{Results}

Scenario analysis

The base-case and alternative scenarios 1,2 and 3 are presented in Table 2. Under the assumptions of the model, the base-case scenario indicates that the prevalence of third-line treatment-eligible GIST is estimated as 1.0 per 100,000 population ( $95 \%$ confidence interval [CI]; 0.7-1.3), and the probability that this figure will remain below 2.0 per 100,000 population is $99.9 \%$. In addition, the prevalence of the total GIST population is estimated as 15.0 per 100,000 population (95\% CI; $11.2-$ 19.8). The total number of patients living after suffering GIST (all stages) is estimated at 9,365 (95\% CI; 6,953$12,325)$ and with third-line treatment-eligible GIST is 598 (95\% CI: 432-804). Our model estimated the absolute number of patients receiving imatinib as 1,422 (95\% CI; $838-$ 2,368) and receiving sunitinib as 599 (95\% CI: 435-789).

By comparison, the first alternative scenario, which assumes a higher yearly incidence of GIST of 1.5 per 100,000 population [4], provides a prevalence estimate of third-line treatment-eligible GIST eligible patients of 1.4 per 100,000 population $(95 \% \mathrm{CI} ; 1.1-1.7)$ with a corresponding probability of remaining below the 2.0 per 100,000 population threshold of $99.6 \%$. Figures for the second alternative scenario, which assumes a longer third-line treatment-eligible GIST survival of 1.5 years, are higher than those of the base-case and the first alternative scenario with respect to third-line treatmenteligible GIST prevalence and lower in terms of probability of the third-line treatment-eligible GIST prevalence remaining below 2.0 per 100,000 population (threshold). The third alternative scenario, which assumes both higher incidence and longer third-line treatment-eligible GIST survival, produces a third-line treatment-eligible GIST prevalence of 2.2 per 100,000 population (95\% CI: $1.5-3.2$ ) and a probability of $37.9 \%$ that the third-line 
Table 2 Scenario results produced by the proposed model, with $95 \%$ confidence intervals (CI)

\begin{tabular}{|c|c|c|c|c|c|c|c|}
\hline & $\begin{array}{l}\text { Third-line treatment-eligible } \\
\text { GIST* population prevalence } \\
\text { per } 100000 \text { persons }(95 \% \mathrm{Cl})\end{array}$ & $\begin{array}{l}\text { Probability that third-line } \\
\text { treatment-eligible GIST } \\
\text { population is below } 2 \\
\text { per } 100000 \text { persons }\end{array}$ & $\begin{array}{l}\text { Absolute number } \\
\text { third-line treatment- } \\
\text { eligible GIST population } \\
(95 \% \mathrm{Cl})\end{array}$ & $\begin{array}{c}\text { Total GIST } \\
\text { population } \\
\text { prevalence per } \\
100000 \text { persons } \\
(95 \% \mathrm{Cl})\end{array}$ & $\begin{array}{l}\text { Absolute number } \\
\text { total GIST } \\
\text { population }(95 \% \mathrm{Cl})\end{array}$ & $\begin{array}{l}\text { Absolute number } \\
\text { of GIST patients on } \\
\text { imatinib }(95 \% \mathrm{Cl})\end{array}$ & $\begin{array}{l}\text { Absolute number } \\
\text { of GIST patients on } \\
\text { sunitinib }(95 \% \mathrm{Cl})\end{array}$ \\
\hline $\begin{array}{l}\text { Base-case Scenario GIST } \\
\text { Incidence: } 1.053 / 100000 \\
\text { person-years }(p-y) \\
\text { Third-line treatment-eligible } \\
\text { GIST survival: } 0.77 \text { yrs }\end{array}$ & $0.96(0.69-1.29)$ & $99.9 \%$ & $598(432-804)$ & $15.04(11.2-19.8)$ & $9365(6953-12325)$ & $1422(838-2368)$ & $599(435-789)$ \\
\hline $\begin{array}{l}\text { Alternative Scenario } 1 \text { GIST } \\
\text { Incidence: } 1.5 / 100000 \text { p-y } \\
\text { Third-line treatment-eligible } \\
\text { GIST survival: } 0.77 \text { yrs }\end{array}$ & $1.37(1.06-1.73)$ & $99.6 \%$ & $851(662-1080)$ & $21.9(13.9-31.7)$ & $13364(10697-16383)$ & $2020(1,252-3,258)$ & $855(670-1067)$ \\
\hline $\begin{array}{l}\text { Alternative Scenario } 2 \text { GIST } \\
\text { Incidence: } 1.053 / 100000 \text { p-y } \\
\text { Third-line treatment-eligible } \\
\text { GIST survival: } 1.5 \text { yrs }\end{array}$ & $1.53(1.00-2.29)$ & $90.6 \%$ & $954(622-1428)$ & $15.6(11.6-20.3)$ & 9699 (7227 - 12633) & $1410(832-2338)$ & $602(437-802)$ \\
\hline $\begin{array}{l}\text { Alternative Scenario } 3 \text { GIST } \\
\text { Incidence: } 1.5 / 100000 \mathrm{p}-\mathrm{y} \\
\text { Third-line treatment-eligible } \\
\text { GIST survival } 1.5 \text { yrs }\end{array}$ & $2.18(1.50-3.18)$ & $37.9 \%$ & $1357(933-1984)$ & $22.3(17.7-27.4)$ & $13886(1068-17069)$ & $2020(1259-3282)$ & $854(674-1061)$ \\
\hline
\end{tabular}


treatment-eligible GIST prevalence will remain below the threshold.

\section{Univariate sensitivity analysis}

Univariate sensitivity analysis performed on the basecase and alternative scenarios demonstrate that the initial incidence of GIST and third-line treatment-eligible GIST survival were most influential on the prevalence of third-line treatment-eligible GIST, as illustrated in the tornado diagram (Figure 2). Model parameters associated with survival on imatinib and sunitinib had the least influence on prevalence of third-line treatmenteligible GIST.

\section{Threshold analysis}

To better quantify the risk associated with the two most influential parameters, we determined the threshold incidence and third-line treatment-eligible GIST survival that would cause the third-line treatment-eligible GIST prevalence to exceed 2.0 per 100,000, while all other parameters were fixed at the base-case values. This analysis showed that the incidence of GIST would need to be 2.2 per 100,000 population or higher for the third-line treatment-eligible GIST population to exceed the threshold. The third-line treatment-eligible GIST transition rate would have to be 0.31 or higher, corresponding to a median survival after imatinib and sunitinib failure of at least 2.2 years.

\section{Discussion}

We employed a modelling approach to estimate the overall number and prevalence of metastatic/unresectable GIST patients in the UK and those who failed on currently licensed treatments. The model demonstrated that, under a plausible set of assumptions (base-case scenario) of disease incidence and survival, the prevalence of third-line treatment-eligible GIST is 1.0 (95\% CI; 0.71.3) per 100,000 , with a $99.9 \%$ likelihood of being below the 2 per 100,000 population threshold for ultra-orphan disease status in the UK. As data values reported in published studies which informed our model parameters are subject to great variation, we examined three alternative sets of assumptions.

When we raised the assumed yearly incidence of GIST to the highest levels reported in Western countries (1.5 per 100,000 persons), the probability that third-line treatment-eligible GIST prevalence remained below the ultra-orphan disease threshold was virtually unchanged (99.6\%). This scenario may be plausible given that estimates of the annual incidence of GIST may rise with improved diagnosis of tumours that are tested for c-KIT. [22] Because a new effective treatment line would prolong life in the third-line treatment-eligible GIST and therefore increase prevalence, it was important to assess the longer patient survival impact on the third-line treatment-eligible GIST prevalence. By assuming 1.5 years of survival in the third-line treatment-eligible GIST state, we estimated a 90.6\% probability that its prevalence was below the ultraorphan disease threshold. Only when assuming both higher GIST incidence and longer third-line treatmenteligible GIST survival we obtained a $37.9 \%$ probability of remaining below the threshold of interest.

Sensitivity analysis showed that initial GIST incidence and third-line treatment-eligible GIST survival were the most influential variables on the third-line treatmenteligible GIST prevalence estimate, while threshold analysis showed that only under extreme assumptions of these two parameters (GIST incidence greater than 2.2 per 100,000 population or third-line treatment-eligible GIST survival greater than 2.2 years) would the number of third-line treatment-eligible GIST patients surpass the UK ultra-orphan disease threshold. We did not explore

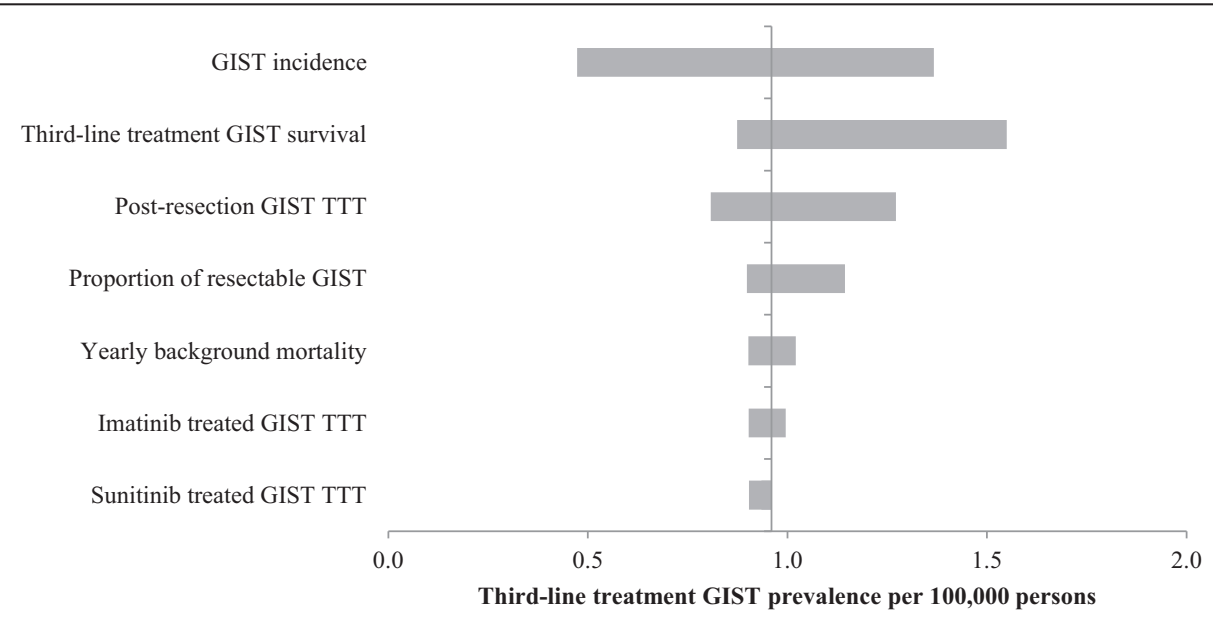

Figure 2 Tornado diagram: Univariate sensitivity analysis for base-case scenario (low incidence and short third-line treatment-eligible GIST survival). GIST = gastrointestinal stromal tumour; $\Pi \pi$ = time to transition. 
further other model parameters in this respect. Varying estimates of post-resection GIST TTT, imatinib-treated GIST TTT, sunitinib-treated GIST TTT and the proportion of resectable GIST did not greatly influence our study findings.

The model predicted the total number of patients living after suffering GIST in the base-case to be 9,365 $(95 \% \mathrm{CI} ; 6,953-12,325)$ and the number of GIST patients taking imatinib as $1,422(95 \% \mathrm{CI}$; $838-2,368)$ or sunitinib as 599 (95\% CI: 435-789).

The understanding of the aetiology and management of GIST has evolved since it was first differentiated among other soft tissue sarcomas and two lines of therapy became available for patients with metastatic or unresectable tumours. However, for a proportion of patients, these therapies eventually fail and patients who exhaust their treatments are left with re-challenging with higher imatinib dose or best supportive care. Several potential third-line treatment drugs [23-25] could be candidates for orphan or ultra-orphan disease treatment status. Orphan and ultra-orphan disease status have implications on how public funding supports the provision of treatments, and the speed of access to new treatments for suitable patients. There could be a case for potential treatments after imatinib and sunitinib failure given the low number of patients at third-line treatment-eligible GIST.

The major limitation of the study is the face validity of the model structure and the structure's inherent assumptions on treatment pathways; however, this study presents a model, understood as a simplified and imperfect description of reality, which estimates the number of subjects at each stage of GIST treatment, based on model parameters available from the literature. Another limitation we encountered was that data needed to inform the model parameters were sparse or unsuitable, which has also been reported in economic modelling studies [26-30]. This limitation is common in modelling studies since it is not always possible to inform all of the model parameters, considering that the samples of the available studies are small [27], the evidence for the model is obtained from only one study [26] or data are used from other countries and applied to the country of interest due to lack of local evidence [29].

Some of the reviewed studies reported on important prognostic variables (i.e., mitotic count, genetic markers) that identify heterogeneous subgroups within the GIST patient population. Our model did not explicitly account for these subgroups as this would have necessitated stratum-specific TTT estimates that were mostly unavailable. As a result, we have given preference to publications with large sample sizes where a pool of GIST patients with a mix of those variables can occur, that is, studies with heterogeneous patient populations (i.e., different treatment histories, stages of GIST) and response criteria. Nonetheless, sensitivity and scenario analysis showed that the importance of data uncertainty mattered mainly for initial incidence of GIST and third-line treatment-eligible GIST survival.

We acknowledge that the model's structure, where all patients transition through the treatment states sequentially, and assuming that patients cannot skip a particular treatment line, can be questioned. Another modelling study included up to seven plausible treatment pathways for patients with GIST which also depended on limited data for the proportions of patients following each pathway, and required assumptions for death rates and state transition probabilities [4]. We also assumed GIST as not curable, so all subjects diagnosed with GIST could not exit the GIST population. Nevertheless, the post-resection GIST TTT are widely distributed and a long postresection GIST TTT (longer than the life expectancy) can be assumed as cured GIST. Both of these assumptions are conservative since patients remain in the model for longer, therefore, leading to overestimation of GIST-related state prevalences. Our model did not explicitly include pathways for adjuvant and neoadjuvant use of tyrosine kinase inhibitors. These therapeutic strategies can be considered a combination of the two proposed model pathways.

\section{Conclusion}

Despite the study limitations, there is a very high probability of third-line treatment-eligible GIST prevalence being below 2.0 per 100,000 population in the UK, therefore, remaining below the ultra-orphan disease threshold. This is relevant because provision of orphan and ultra-orphan disease status can affect the speed of access to new treatments for suitable patients.

\section{Additional file}

Additional file 1: Appendices Appendix I. Method Used to Calculate Incidence of GIST in UK. Appendix II. Model Specifications. Appendix III. Key Data Sources for Model Parameters. Appendix IV. Literature Search Strategy [54-58].

\section{Abbreviations}

Cl: Confidence interval; EU: European Union; GIST: Gastrointestinal stromal tumours; ICD-O: International Classification of Disease for Oncology; NICE: National Institute for Health and Care Excellence; OS: Overall survival; PFS: Progression-free survival; PSA: Probabilistic sensitivity analysis; TTP: Time to tumour progression; TाT: Time to transition; UK: United Kingdom; US: United States; WMCIU: West Midlands Cancer Intelligence Unit.

\section{Competing interests}

JMSA, JCR, KD, JMK and AM were employees of Evidera (JMSA, JMK and AM are currently former Evidera employees). Evidera is a global scientific and medical affairs organization that partners with life science companies and professionals. ST, DM and PA were Bayer employees. (ST, PA and JCR are currently former Bayer employees). Bayer is a global enterprise with core competencies in the fields of health care, agriculture and high-tech materials. Bayer is conducting research on GIST therapy.

Bayer sponsored this research. 


\section{Authors' contributions}

AM conceived the study; JMSA coordinated the study; JMSA conducted the literature search and extraction; JCR and KD participated in the literature search and extraction; JMK collected data from registers; JMSA, JCR and KD developed the model structure; AM, ST, DM and PA reviewed the model structure; KD carried out the model analyses (parameter estimation, sensitivity analyses and threshold analyses); JCR carried out additional data analyses; AM and JMK participated in additional data analyses; JMSA, JCR and KD drafted different sections of the manuscript; AM, JMK, ST, DM and PA helped to develop the draft manuscript; all authors reviewed and provided feedback to the manuscript, and all authors read and approved the final manuscript.

\section{Authors' information}

JMSA (PhD) Observational Research Manager at Amgen

JCR (MD, DrPH, MBA, MSc) Research Scientist and Epidemiologist, Epidemiology and Database Analytics at Evidera

JMK (PhD) Associate Director, Epidemiology at Takeda Pharmaceuticals

AM (MSC, FSS) Director, Epidemiology at OXON Epidemiology

$\mathrm{KD}(\mathrm{PhD})$ Research Scientist, Health Economics at Evidera

ST (MSc) Director, Global Value Access \& Policy at Amgen

DM (MSc) Senior Health Economist at Bayer plc

PA (PhD) Senior Vice President and Managing Director at Alimera Sciences.

\section{Acknowledgement}

We would like to acknowledge the West Midlands Cancer Intelligence Unit (WMCIU) (currently Public Health England Knowledge and Intelligence Team West Midlands) and Mr Matthew Francis, Cancer Analysis Development Manager at WMCIU, for extracting the data that were used to inform part of our model and answering our questions.

Each of the authors was funded by his or her employer at the time of study conduct and manuscript preparation.

This research and this manuscript were commissioned and sponsored by Bayer. Study design, data collection, analysis and interpretation, and writing of the manuscript were conducted by Evidera authors. Bayer authors reviewed and provided feedback. Submission of the resulting manuscript to a scientific journal was included in the initial project scope.

\section{Author details}

${ }^{1}$ Health Economics and Epidemiology, Evidera, Metro Building, 6th floor, No.1 Butterwick, London W6 8DL, UK. ${ }^{2}$ Global Market Access, Bayer Pharma AG, Berlin S157, 03, 305, Germany. ${ }^{3}$ Health Economics, Bayer plc, Strawberry Hill, Newbury RG14 1JA, UK.

Received: 30 January 2013 Accepted: 12 May 2014

Published: 24 May 2014

\section{References}

1. Kostka R, Gurlich R, Koldova L: Gastrointestinal stromal tumors (GIST): a single center experience. Acta Chir Belg 2012, 112:33-39.

2. Steigen SE, Eide TJ: Gastrointestinal stromal tumors (GISTs): a review. APMIS 2009, 117:73-86.

3. Ahmed I, Welch NT, Parsons SL: Gastrointestinal stromal tumours (GIST) 17 years experience from mid trent region (United Kingdom). Eur J Surg Oncol 2008, 34:445-449.

4. Hislop J, Quayyum Z, Elders A, Fraser C, Jenkinson D, Mowatt G, Sharma P, Vale L, Petty R: Systematic Review of the Clinical and Cost-Effectiveness of Imatinib at Escalated Doses of $600 \mathrm{mg} /$ day or $800 \mathrm{mg} /$ day for the Treatment of Unresectable and/or Metastatic Gastrointestinal Stromal Tumours Which Have Progressed on Treatment at a Dose of $400 \mathrm{mg} /$ day. In Aberdeen HTA Group. Aberdeen, UK: Institute of Applied Health Sciences, University of Aberdeen; 2010.

5. Nilsson B, Bumming P, Meis-Kindblom JM, Oden A, Dortok A, Gustavsson B, Sablinska K, Kindblom LG: Gastrointestinal stromal tumors: the incidence, prevalence, clinical course, and prognostication in the preimatinib mesylate era-a population-based study in western Sweden. Cancer 2005, 103:821-829.

6. Chan KH, Chan CW, Chow WH, Kwan WK, Kong CK, Mak KF, Leung MY, Lau LK: Gastrointestinal stromal tumors in a cohort of Chinese patients in Hong Kong. World I Gastroenterol 2006, 12:2223-2228.
7. Aparicio T, Boige V, Sabourin JC, Crenn P, Ducreux M, Le Cesne A, Bonvalot $S$ : Prognostic factors after surgery of primary resectable gastrointestinal stromal tumours. Eur J Surg Oncol 2004, 30:1098-1103.

8. Brabec P, Sufliarsky J, Linke Z, Plank L, Mrhalova M, Pavlik T, Klimes D, Gregor J: A whole population study of gastrointestinal stromal tumors in the Czech Republic and Slovakia. Neoplasma 2009, 56:459-464.

9. Braconi C, Bracci R, Bearzi I, Bianchi F, Costagliola A, Catalani R, Mandolesi A, Ranaldi R, Galizia E, Cascinu S, Rossi G, Giustini L, Latini L, Valeri N, Cellerino R: KIT and PDGFRalpha mutations in 104 patients with gastrointestinal stromal tumors (GISTs): a population-based study. Ann Oncol 2008, 19:706-710.

10. Bumming P, Ahlman H, Andersson J, Meis-Kindblom JM, Kindblom LG, Nilsson B: Population-based study of the diagnosis and treatment of gastrointestinal stromal tumours. Br J Surg 2006, 93:836-843.

11. Mucciarini C, Rossi G, Bertolini F, Valli R, Cirilli C, Rashid I, Marcheselli L, Luppi G, Federico M: Incidence and clinicopathologic features of gastrointestinal stromal tumors. A population-based study. BMC Cancer 2007, 7:230. doi:10.1186/1471-2407-7-230.

12. Perez EA, Livingstone AS, Franceschi D, Rocha-Lima C, Lee DJ, Hodgson N, Jorda M, Koniaris LG: Current incidence and outcomes of gastrointestinal mesenchymal tumors including gastrointestinal stromal tumors. J Am Coll Surg 2006, 202:623-629.

13. Pisters PW, Blanke CD, von Mehren M, Picus J, Sirulnik A, Stealey E, Trent JC, re GSC: A USA registry of gastrointestinal stromal tumor patients: changes in practice over time and differences between community and academic practices. Ann Oncol 2011, 22:2523-2529.

14. Rutkowski P, Nowecki ZI, Michej W, Debiec-Rychter M, Wozniak A, Limon J, Siedlecki J, Grzesiakowska U, Kakol M, Osuch C, Polkowski M, Gluszek S, Zurawski Z, Ruka W: Risk criteria and prognostic factors for predicting recurrences after resection of primary gastrointestinal stromal tumor. Ann Surg Oncol 2007, 14:2018-2027.

15. Yan BM, Kaplan GG, Urbanski S, Nash CL, Beck PL: Epidemiology of gastrointestinal stromal tumors in a defined Canadian health region: a population-based study. Int J Surg Pathol 2008, 16:241-250.

16. Quek R, George S: Gastrointestinal stromal tumor: a clinical overview. Hematol Oncol Clin North Am 2009, 23:69-78.

17. Proposal for appraising orphan drugs and ultra-orphan drugs. Available at http://www.nice.org.uk/niceMedia/pdf/smt/120705item4.pdf.

18. Citizens council report ultra orphan drugs. Available at http://www.nice. org.uk/page.aspx?o=240951.

19. The West Midlands Cancer Intelligence Unit (WMCIU) (currently Public Health England Knowledge and Intelligence Team West Midlands): GISTs 2007-2010 extracted in March 2012.

20. Historic and projected mortality data (1951 to 2060) from the UK life tables, 2010-based. Historic and projected mortality rates (qx) from the 2010-based UK life tables - principal projection. http://www.ons.gov.uK/ ons/publications/re-reference-tables.html?edition=tcm\%3A77-257453.

21. Goettsch WG, Bos SD, Breekveldt-Postma N, Casparie M, Herings RM, Hogendoorn PC: Incidence of gastrointestinal stromal tumours is underestimated: results of a nation-wide study. Eur J Cancer 2005, 41:2868-2872.

22. Demetri GD: Targeting c-kit mutations in solid tumors: scientific rationale and novel therapeutic options. Semin Oncol 2001, 28:19-26.

23. George S, von Mehren M, Heinrich MC, Wang Q, Corless CL, Butrynski JE, Morgan JA, Wagner AJ, Choy E, Tap WD, Manola J, Yap JT, Van Den Abbeele AD, Solomon S, Fletcher JA, Demetri GD: A multicenter phase II study of regorafenib in patients (pts) with advanced gastrointestinal stromal tumor (GIST), after therapy with imatinib (IM) and sunitinib (SU). J Clin Oncol (ASCO Meeting Abstract) 2011, 29(15 suppl; May 20 Supplement):abstr 10007.

24. Kindler HL, Campbell NP, Wroblewski K, Maki RG, D'Adamo DR, Chow WA, Gandara DR, Antonescu C, Stadler WM, Vokes EE: Sorafenib (SOR) in patients (pts) with imatinib (IM) and sunitinib (SU)-resistant (RES) gastrointestinal stromal tumors (GIST): final results of a University of Chicago Phase II Consortium trial. J Clin Oncol (ASCO Meeting Abstract) 2011, 29(15 suppl;May 20 Supplement):abstr 10009.

25. Trent JC, Wathen $K$, von Mehren M, Samuels BL, Staddon AP, Choy E, Butrynski JE, Chugh R, Chow WA, Rushing DA, Forscher CA, Baker LH, Schuetze S, Sarcoma Alliance for Research through Collaboration: A phase II study of dasatinib for patients with imatinib-resistant gastrointestinal stromal tumor (GIST). J Clin Oncol (ASCO Meeting Abstract) 2011, 29(15 suppl;May 20 Supplement):abstr 10006.

26. Bond M, Hoyle M, Moxham T, Napier M, Anderson R: Sunitinib for the treatment of gastrointestinal stromal tumours: a critique of the submission from Pfizer. Health Technol Assess 2009, 13:69-74. 
27. Contreras-Hernandez I, Mould-Quevedo JF, Silva A, Salinas-Escudero G, Villasis-Keever MA, Granados-Garcia V, Davila-Loaiza G, Petersen JA, Garduno-Espinosa J: A pharmaco-economic analysis of second-line treatment with imatinib or sunitinib in patients with advanced gastrointestinal stromal tumours. Br J Cancer 2008, 98:1762-1768.

28. Mabasa VH, Taylor SC, Chu CC, Moravan V, Johnston K, Peacock S, Knowling M: Verification of imatinib cost-effectiveness in advanced gastrointestinal stromal tumor in British Columbia (VINCE-BC study). J Oncol Pharm Pract 2008, 14:105-112

29. Paz-Ares L, Garcia del Muro X, Grande E, Gonzalez P, Brosa M, Diaz S: Costeffectiveness analysis of sunitinib in patients with metastatic and/or unresectable gastrointestinal stroma tumours (GIST) after progression or intolerance with imatinib. Clin Trans/ Oncol 2008, 10:831-839.

30. Wilson J, Connock M, Song F, Yao G, Fry-Smith A, Raftery J, Peake D: Imatinib for the treatment of patients with unresectable and/or metastatic gastrointestinal stromal tumours: systematic review and economic evaluation. Health Technol Assess 2005, 9:1-142.

31. Rubio J, Marcos-Gragera R, Ortiz MR, Miro J, Vilardell L, Girones J, Hernandez-Yague X, Codina-Cazador A, Bernado L, Izquierdo A, Colomer R: Population-based incidence and survival of gastrointestinal stromal tumours (GIST) in Girona, Spain. Eur J Cancer 2007, 43:144-148.

32. Tryggvason G, Gislason HG, Magnusson MK, Jonasson JG: Gastrointestinal stromal tumors in Iceland, 1990-2003: the icelandic GIST study, a population-based incidence and pathologic risk stratification study. Int J Cancer 2005, 117:289-293.

33. Witkowski ER, Smith JK, Ng S, McDade TP, Shah SA, Al-Refaie WB, Tseng JF: Nationwide trends in diagnosis and outcomes of gastrointestinal stromal tumors in the era of targeted therapy. J Clin Oncol (Gastrointestinal Cancers Symposium Meeting Abstract) 2011, 29(4 suppl; Feb 1 Supplement):abstr 121.

34. Joensuu H, Vehtari A, Riihimaki J, Nishida T, Steigen SE, Brabec P, Plank L, Nilsson B, Cirilli C, Braconi C, Bordoni A, Magnusson MK, Linke Z, Sufliarsky J, Federico M, Jonasson JG, Dei Tos AP, Rutkowski P: Risk of recurrence of gastrointestinal stromal tumour after surgery: an analysis of pooled population-based cohorts. Lancet Oncol 2012, 13:265-274.

35. Gold JS, Gonen M, Gutierrez A, Broto JM, Garcia-del-Muro X, Smyrk TC, Maki RG, Singer S, Brennan MF, Antonescu CR, Donohue JH, DeMatteo RP: Development and validation of a prognostic nomogram for recurrence-free survival after complete surgical resection of localised primary gastrointestinal stromal tumour: a retrospective analysis. Lancet Oncol 2009, 10:1045-1052.

36. Rutkowski P, Bylina E, Wozniak A, Nowecki ZI, Osuch C, Matlok M, Switaj T, Michej W, Wronski M, Gluszek S, Kroc J, Nasierowska-Guttmejer A, Joensuu $\mathrm{H}$ : Validation of the Joensuu risk criteria for primary resectable gastrointestinal stromal tumour - the impact of tumour rupture on patient outcomes. Eur J Surg Oncol 2011, 37:890-896.

37. Dematteo RP, Gold JS, Saran L, Gonen M, Liau KH, Maki RG, Singer S, Besmer P, Brennan MF, Antonescu CR: Tumor mitotic rate, size, and location independently predict recurrence after resection of primary gastrointestinal stromal tumor (GIST). Cancer 2008, 112:608-615.

38. Mochizuki Y, Kodera Y, Ito S, Yamamura Y, Kanemitsu Y, Shimizu Y, Hirai T, Yasui $K$, Inada $K$, Kato $T$ : Treatment and risk factors for recurrence after curative resection of gastrointestinal stromal tumors of the stomach. World J Surg 2004, 28:870-875.

39. Azribi F, Razak A, Dildey P, Adam J, Wilsdon J, Verrill M: Imatinib in Gastrointestinal Stromal Tumour: Northern Cancer Network Experience. In Ecancer. 2009. 3:162 doi:10.3332/ecancer.2010.162.

40. Demetri GD, von Mehren M, Blanke CD, Van den Abbeele AD, Eisenberg B, Roberts PJ, Heinrich MC, Tuveson DA, Singer S, Janicek M, Fletcher JA, Silverman SG, Silberman SL, Capdeville R, Kiese B, Peng B, Dimitrijevic S, Druker BJ, Corless C, Fletcher CDM, Joensuu $\mathrm{H}$ : Efficacy and safety of imatinib mesylate in advanced gastrointestinal stromal tumors. N Engl J Med 2002, 347:472-480

41. Blanke CD, Demetri GD, von Mehren M, Heinrich MC, Eisenberg B, Fletcher JA Corless CL, Fletcher CD, Roberts PJ, Heinz D, Wehre E, Nikolova Z, Joensuu H: Long-term results from a randomized phase II trial of standard- versus higher-dose imatinib mesylate for patients with unresectable or metastatic gastrointestinal stromal tumors expressing KIT. J Clin Oncol 2008, 26:620-625.

42. Bonvalot $\mathrm{S}$, Eldweny $\mathrm{H}$, Pechoux CL, Vanel D, Terrier P, Cavalcanti A, Robert C, Lassau N, Cesne AL: Impact of surgery on advanced gastrointestinal stromal tumors (GIST) in the imatinib era. Ann Surg Oncol 2006, 13:1596-1603.

43. Al-Batran SE, Hartmann JT, Heidel F, Stoehlmacher J, Wardelmann E, Dechow C, Dux M, Izbicki JR, Kraus T, Fischer T, Jager E: Focal progression in patients with gastrointestinal stromal tumors after initial response to imatinib mesylate: a three-center-based study of 38 patients. Gastric Cancer 2007, 10:145-152.

44. Cohen MH, Farrell A, Justice R, Pazdur R: Approval summary: imatinib mesylate in the treatment of metastatic and/or unresectable malignant gastrointestinal stromal tumors. Oncologist 2009, 14:174-180.

45. Reichardt P, Kang Y, Ruka W, Seddon B, Guerreiro A, Breazna A, Lowry S, Demetri GA: Detailed analysis of survival and safety with sunitinib (SU) in a worldwide treatment-use trial of patients with advanced GIST. J Clin Oncol (ASCO Meeting Abstract) 2008, 26(15 suppl; May 20 Supplement):abstr 10548

46. Demetri GD, van Oosterom AT, Garrett CR, Blackstein ME, Shah MH, Verweij J, McArthur G, Judson IR, Heinrich MC, Morgan JA, Desai J, Fletcher CD, George S, Bello CL, Huang X, Baum CM, Casali PG: Efficacy and safety of sunitinib in patients with advanced gastrointestinal stromal tumour after failure of imatinib: a randomised controlled trial. Lancet 2006, 368:1329-1338.

47. Blay JY: New paradigms in gastrointestinal stromal tumour management. Ann Oncol 2009, 20:i18-i24.

48. Raut CP, Wang Q, Manola J, Morgan JA, George S, Wagner AJ, Butrynski JE, Fletcher CD, Demetri GD, Bertagnolli MM: Cytoreductive surgery in patients with metastatic gastrointestinal stromal tumor treated with sunitinib malate. Ann Surg Oncol 2010, 17:407-415.

49. Italiano A, Cioffi A, Coco P, Maki RG, Schoffski P, Rutkowski P, Le Cesne A Duffaud F, Adenis A, Isambert N, Bompass E, Blay JY, Casali P, Keohan ML, Toulmonde M, Antonescu CR, Debiec-Rychter M, Coindre JM, Bui B: Patterns of care, prognosis, and survival in patients with metastatic gastrointestinal stromal tumors (GIST) refractory to first-line imatinib and second-line sunitinib. Ann Surg Oncol 2012, 19:1551-1559.

50. Reichardt P, Blay J, Gelderblom H, Schlemmer M, Demetri GD, Bin Bui N, McArthur GA, Yazji S, Hsu Y, Rutkowski P: Phase III trial of nilotinib in patients with advanced gastrointestinal stromal tumor (GIST): First results from ENEST g3. J Clin Oncol (ASCO Meeting Abstract) 2010, 28(15 suppl; May 20 Supplement):abstr 10017.

51. Nishida T, Sawaki A, Doi T, Yamada Y, Komatsu Y, Kanda T, Kakeji Y, Onozawa Y, Yamasaki M, Ohtsu A: Phase II trial of nilotinib as third-line therapy for gastrointestinal stromal tumor (GIST) patients in Japan. $J$ Clin Oncol (ASCO Meeting Abstract) 2010, 28(15 suppl; May 20 Supplement):abstr 10015.

52. Montemurro M, Schoffski $P$, Reichardt $P$, Gelderblom H, Schutte J, Hartmann J, von Moos R, Seddon B, Joensuu H, Wendtner CM, Weber E, Grünwald V, Roth A, Leyvraz $\mathrm{S}$ : Nilotinib in the treatment of advanced gastrointestinal stromal tumours resistant to both imatinib and sunitinib. Eur J Cancer 2009, 45:2293-2297.

53. Wiebe L, Kasza KE, Maki RG, D'Adamo DR, Chow WA, Wade JL III, Agamah E, Stadler WM, Vokes EE, Kindler HL: Activity of sorafenib (SOR) in patients (pts) with imatinib (IM) and sunitinib (SU)-resistant (RES) gastrointestinal stromal tumors (GIST): a phase II trial of the University of Chicago Phase II Consortium. J Clin Oncol (ASCO Meeting Abstract) 2008, 26(15 suppl; May 20 Supplement):abstr 10502

54. van Belle G, Fisher LD, Heagerty PJ, Lumley T: Rates and proportions. In Biostatistics: a Methodology for the Health Sciences. 2nd edition. Hoboken, New Jersey, USA: John Wiley \& Sons, Inc; 2004:640-653.

55. Lawrence G, O'Sullivan E, Kearins O, Tappenden N, Martin K, Wallis M: Screening histories of invasive breast cancers diagnosed 1989-2006 in the West Midlands, UK: variation with time and impact on 10-year survival. J Med Screen 2009, 16:186-192.

56. Reid R, O'Dywer P, MacDuff E, White J, Cowie F, Currie D, Wall L, Niblock P, Walsh S: Guidelines for the Management of Gastrointestinal Stromal Tumours (GIST) in Scotland. Glasgow: Scottish Sarcoma Network; 2009. Available at http://www.imagingnetwork.scot.nhs.uk/wp-content/2010/02/Scottish-GISTguidelines_NOV545_no-code_041209.pdf.

57. Kindblom LG: Education session E450, oral presentation "Gastrointestinal stromal tumors diagnosis, epidemiology and prognosis' in"Gastrointestinal stromal tumors: current management and future challenges". Chair: Blanke CD. ASCO. 2003, Available at http://media.asco.org/asco/meetings_education/ module/audio/frame.asp? EventName $=\mathrm{vm} 2003 \& \mathrm{ID}=875 \&$ mediaURL $=/$ media\& ServerName=media.asco.org

58. Nishida T, Takahashi T, Nakajima K, Tsujinaka T, Hirota S: KIT and PDGFRA mutations of gastrointestinal stromal tumor. J Clin Oncol (ASCO Meeting Abstract) 2009, 27(15 suppl; May 20 Supplement):abstr 10560.

\section{doi:10.1186/1471-2407-14-364}

Cite this article as: Starczewska Amelio et al.: Prevalence of gastrointestinal stromal tumour (GIST) in the United Kingdom at different therapeutic lines: an epidemiologic model. BMC Cancer 2014 14:364 